\title{
Complexity in obsessive-compulsive and body dysmorphic disorder - a functional approach to complex difficulties
}

\author{
Oliver Sündermann ${ }^{1,2 *}$ and David Veale $\mathrm{e}^{1,3,4}$ \\ ${ }^{1}$ Department of Psychology, National University of Singapore, 02-24, 9 Arts Link, 117570, Singapore \\ ${ }^{2}$ The Priory North London, Obsessional Disorders Department, London N14 6RA, UK \\ ${ }^{3}$ The Institute of Psychiatry, Psychology and Neurosciences, King's College London, De Crespigny \\ Park, London SE5 8AF, UK \\ ${ }^{4}$ Anxiety Disorders Residential Unit, Bethlem Royal Hospital, London BR3 3BX, UK
}

Received 8 June 2017; Accepted 22 August 2017

\begin{abstract}
Obsessive-compulsive disorder (OCD) and related disorders such as body dysmorphic disorder (BDD) can take many different forms of presentations. The term 'complex' is common and inconsistently used in both OCD and BDD. Practitioners often refer to complex OCD or BDD when patients present with severe co-morbid problems, often in the context of personality difficulties, dissociation, difficult early relationships and trauma; or when the illness is chronic and debilitating with previous multiple treatment failures. Current best-evidence treatment protocols for both disorders focus heavily on exposure and response prevention (E/RP) but with moderate success, particularly in patients who are deemed 'complex', and often those with relevant shame and/or disgust-based past experiences. The aim of the present paper is to (a) describe factors that contribute to complexity in OCD and BDD, and (b) link these with theory and practice. We emphasize the importance of understanding both the function of OCD and BDD-related behaviours (rather than the content of obsessions or compulsion), and the context in which they occur such as the family. We illustrate complexity in OCD and BDD using real case material, using a functional and contextual approach to formulate the client's difficulties, and demonstrate how E/RP can be enhanced successfully with imagery rescripting, family work, and compassionfocused therapy.
\end{abstract}

Keywords: OCD, BDD, OCRD, trauma, imagery

\section{Introduction}

Obsessive-compulsive and related disorders (OCRDs) can take vastly heterogeneous presentations. The different phenomenologies are well known, and traditionally there has been an emphasis on the content of obsessions and compulsions, and much less about the

\footnotetext{
*Author for correspondence: Dr Oliver Sündermann, Department of Psychology, National University of Singapore and The Priory North London, UK (email: psymos@nus.edu.sg).
} 
functions of OC symptoms. This is also reflected in the DSM-5, which groups OCRDs based on similarity in phenomenology, their co-morbidity and family history. Various attempts have been undertaken to cluster sub-types of OCRDs, or categorize different symptom clusters into subgroups (McKay et al., 2004). For example, the OC literature differentiates between 'contamination and washing OC', 'harm obsessions and checking rituals', 'obsessions without overt compulsions', and so forth. Besides different manifestations, OCRD can vary widely in terms of severity and complexity. A database search (PsycINFO, PubMed, OVID Medline, Google Scholar) revealed 64 studies using the term 'complex OCD' or 'complex obsessive compulsive disorder' anywhere in the article, whereas 'complex BDD', or 'complex body dysmorphic disorder' only retrieved one relevant study, and no study was retrieved searching for 'complex obsessive-compulsive and related disorders' or 'complex OCRD'. To the best of our knowledge, the terms complex OCD, complex BDD or complex OCRD have not been defined in the literature.

Despite the lack of definition and the sparse use of the term 'complex' in the OCRD literature, practitioners widely use the term in clinical practice, for example in ward discussions, conferences or funding panels. Clinicians might refer to complex OCRDs when patients present with severe co-morbid problems, often in the context of personality and interpersonal difficulties, dissociative experience, difficult early relationships, severe attachment difficulties, and trauma; or when the illness is chronic and debilitating with previous multiple treatment failures. Therefore the term 'complex OCRD' may be used colloquially to refer to people in a variety of circumstances with multiple accompanying difficulties to their obsessive-compulsive problems which interact with primary OCD/BDD to incur complexity. Note that complexity does not equal severity or chronicity of problems; for example, someone with severe OCD may not experience any co-morbid difficulties and as such shall not be referred to as complex. Similalry, complexity does not equal 'treatmentresistant' or 'treatment-refractory', both of which are technical terms used in UK Mental Health to refer to patients who meet specific funding critiera for so-called highly specialized treatments, namely a score above a certain cut-off on a particular symptom measure (such as the Y-BOCS for OCD), and past failures of adequate treatments (such as cognitive behavioural therapy (CBT) and appropriate medication; for a description of Highly Specialised Services for OCD and BDD in the UK, see Drummond et al., 2008).

In that sense, the terms severity, chronicity or treatment-resistance are mostly referred to as quantitative descriptions (meeting certain diagnostic criteria) whereas complexity is usually referred to as a qualitative description (co-morbid presentations, complicating treatment factors or circumstances). Although these terms have different connotations, there appears to be considerable overlap between them. For example, OCRD patients who also experience significant co-morbid difficulties such as dissociation, personality difficulties or psychotic experiences are usually deemed complex by clinicians and are likely to have experienced chronic and severe difficulties, with multiple past treatment failures and associated challenges (e.g. family accommodation, low insight, and other obstacles to treatment). Thus the most complex difficulties in OCRD are likely to occur in patients with severe and chronic difficulties who have not succeeded in previous treatment courses. In this paper we will explore complexity in OCRD, and focus in particular on OCD and BDD. We will highlight factors that contribute complexity to OCRD, how to formulate complex factors (such as dissociation or psychosis within the context of OCRD), and how to address these in treatment. We are drawing on clinical case material from our work with people suffering from treatmentresistant OCRD. 


\section{Treatment of complex OCRD and evidence base}

Current best-evidence treatment protocols for both disorders focus heavily on CBT and exposure and response prevention (E/RP; Sookman, 2015), but with modest success, particularly in those with severe and longstanding OCRDs. For example, recent outcome data from a specialist OCD out-patient clinic showed that only $39.9 \%$ of their sample of treatment-resistant OCD patients improved over the course of treatment, and only $10.3 \%$ were deemed recovered (Boschen and Drummond, 2012). Similarly, in-patients with severe OCD $(n=29)$, treated in a national specialist clinic, showed symptom reduction of $29 \%$ but on average were still deemed 'severe' at discharge. More recently, Veale and colleagues (2015a) reported longitudinal data from a large group of people with treatment-resistant OCD $(n=$ 472) who had undergone residential treatment, with $69 \%$ showing symptom improvement of at least $25 \%$ at discharge. A recent meta-analysis on residential and in-patient treatments of severe OCD, totalling 2306 patients, revealed overall reductions of a meagre 10.7 points on the Y-BOCS (Veale et al., 2016). There is significantly less outcome research for BDD, with a continuously growing evidence base supporting CBT as a first line treatment. Similar to OCD treatment outcomes, full recovery is rare, particularly for those suffering from complex and severe BDD. Randomized controlled trials (RCTs) suggest mean symptom reduction of around 50\% at 1- and 6-month follow-up (Rosen et al., 1995; Veale et al., 1996, 2014; Wilhelm et al., 2014).

While these outcome studies demonstrate that people with severe and complex OCRD can make significant improvements, the modesty of their recovery, alongside those who fail to respond to CBT or E/RP (Abramowitz et al., 2003; Rufer et al., 2006; Tolin et al., 2004), demand a better understanding, formulation and treatment.

\section{Theoretical and practical advancements}

Recent theoretical advances in the field of OCRD have stressed the importance of understanding the function and motivation of symptoms rather than the content (and its classification) of obsessions and compulsions. For example, Melli et al. (2015) distinguished harm avoidance (HA) and disgust avoidance (DA) in contamination OCD as two distinct motivational 'core dimensions' in an attempt to better understand the heterogeneity of contamination-related OCD symptoms and highlight potential treatment implications. Behaviour therapy has poorer outcomes in OCD without HA (Foa et al., 1999), and similarly those with OCD experiencing high levels of disgust respond less well to CBT than those predominantly suffering from anxiety (Olatunji et al., 2009; Mason and Richardson, 2010). Threat-related dysfunctional beliefs (e.g. over-estimation of threat, beliefs that uncertainty is intolerable, beliefs that one is personally responsible for anticipating and preventing harm) may be less important in contamination fear based upon DA than contamination fear based upon HA (Frost and Steketee, 2002).

Mental contamination is strongly associated with DA, and is linked with past trauma such as victimization, humiliation and betrayal (Rachman, 2010; Warnock-Parkes et al., 2012) and therefore trauma-focused approaches such as reliving, imagery rescripting or eye movement desensitization and reprocessing (EMDR) may improve outcome when added to CBT. While we know that past trauma is a risk factor for OCRDs, we currently know little about the emotional and functional links between OCRD behaviours and past experiences. Both CBT and E/RP focus on the here-and-now to help patients shift dysfunctional appraisals and overcome their fears through cognitive and behavioural interventions. 


\section{Functional and contextual understanding of OCRDs}

Veale and Gilbert (2014) set out to conceptualize BDD within a functional and contextual framework. They emphasize that BDD coping behaviours are highly understandable given the way humans evolved to rapidly respond to threat to protect themselves, and that this rapidity often works on a 'better safe than sorry' principle (Marks, 1987; Gilbert, 1998). They propose moving beyond content-based checklists when assessing OCRDs but also to focus on developing a shared formulation of how one's difficulties have arisen and how past experiences continue to influence a person's current suffering. For example, someone who developed BDD in response to humiliation about her appearance in school is, understandably, likely to experience ongoing shame-based memories that drive threat monitoring and avoidance, particularly when these traumatic memories have not been processed adequately. Equally, someone who developed mental contamination OCD in response to sexual abuse may, again understandably, continue to experience disgust-based memories or sensations that drive attentional processes to threat, avoidance and washing rituals. Feelings of threat and lack of safeness are central in OCRDs, and understanding both the function of threatbased emotions such as anxiety, shame, anger and disgust, and their context may provide new treatment avenues or enhance current protocols.

BDD patients often experience intrusive negative appearance-related images associated with early aversive memories (e.g. being bullied; see Osman et al., 2004) which in turn may drive internal and external threat monitoring and safety-seeking behaviours. Equally, people with OCD experience intrusive images (Speckens et al., 2007), and these can also be linked emotionally with past shame-based experiences that continue to 'haunt' the person. Addressing intrusive images in OCD treatment can lead to significant symptom improvement, as recently demonstrated in single-case experimental case series (Veale et al., 2015b). In this study, 12 OCD patients experiencing intrusive distressing images received a single session of imagery rescripting. At 3-month follow-up, the Y-BOCS had decreased on average from 24.1 pre-treatment to 10.7 , with nine out of 12 patients showing clinical significant change, thus concluding that imagery rescripting may be a promising adjunct to CBT where intrusive images are linked with earlier aversive memories. Similar promising findings have recently been reported in two BDD single-case experimental series (Ritter and Stangier, 2016; Willson et al., 2016) and in a BDD single-case study (Sündermann et al., 2016).

\section{Objectives}

This paper explores different dimensions of 'complexity' in OCRD that we frequently encounter in our work with severe OCRD. We emphasize the importance of understanding both the function of OCD and BDD-related behaviours and the context in which they occur. We demonstrate how CBT and E/RP, which focus on present maintaining factors and beliefs, can be enhanced through understanding the development of the problem, its context and function and how these translate into different therapy techniques such as imagery rescripting, family work and compassion-focused therapy. We hypothesize that complexity often stems from past aversive experiences that are emotionally linked with current suffering. OCRDrelated avoidance and coping behaviours are conceptualized as understandable behaviours in the context of the person's experiences, and aim to keep the person safe but bring about a host of unintended consequences. 


\section{Complex cases}

To demonstrate how complex OCRD presents, and how it can be formulated and treated, we draw on case material from a number of clients we have worked with; all of which were either seen in a national specialist OCRD in-patient or residential clinic in London, UK. Patients consented to publication of their cases. All clients were treated between 2014 and 2016, and received intensive courses of treatment ranging from four to 18 months. We have decided on a variety of OCRD presentations including BDD and different types of OCD such as disgust and harm avoidance. We have also altered minor details of the patient's background and context of their story, without changing the meaning or complexity of their difficulties, to ensure anonymity of their identities. Each case is first presented as a brief vignette, and subsequently discussed with regard to the various complexity factors and treatment implications. The emphasis is on describing and formulating complexity, which is why we have chosen a qualitative and descriptive approach, rather than a quantitative one.

\section{Case 1: 'Eric'}

Eric is a 27-year-old single man with Bosnian Muslim origin who suffers from debilitating OCD characterized by disgust avoidance of his and other people's semen. Eric worries that he might leak and spread semen, and when triggered experiences high levels of shame and disgust, emotionally linked with childhood wet dreams. His relationship with his mother is highly enmeshed to the point that it amounted to a folie à deux ${ }^{1}$ in which OCD was effectively 'transmitted' to her.

\section{Case 2: 'Matt'}

Matt is a 33-year-old married man with two young children (aged 10 and 6). His OCD is characterized by worries about dying from HIV or asbestos. He has long-standing mental health problems stemming from bullying and childhood sexual abuse. Matt also suffers from dissociative identity disorder (DID), depersonalization and derealization disorder (DP/DR), panic disorder, health anxiety, post-traumatic stress disorder (PTSD), obsessive-compulsive personality disorder (OCPD), and has a rare medication intolerance rendering any pharmacological treatment impossible. On admission he was severely underweight $(\mathrm{BMI}=16)$ because of his inability to eat (due to contamination fears).

\footnotetext{
${ }^{1}$ Folie à deux, also referred to as 'shared psychotic disorder' is a rare clinical phenomenon that describes the transference of delusional ideas from a primary affected individual to another individual, usually someone with close emotional ties (see Arnone et al., 2006). DSM-5 includes folie à deux in the section 'other specified schizophrenic spectrum and other psychotic disorders', and describes it as 'delusional symptoms in partner of individual with delusional disorder' (ref. 1, p. 122). Folie à deux sometimes occur in the context of other mental health problems such as OCD (Mergui et al., 2010).
} 


\section{Case 3: 'Hema'}

Hema is a 32-year-old woman suffering from treatment-resistant contamination OCD. She worries about small insects crawling under her skin, and copes with excessive disgust avoidance and washing rituals. Her OCD is linked with prolonged childhood sexual abuse, which is also at the root of her BDD, and disordered eating, and she experienced daily dissociative flashbacks reliving early abuse-related memories, during which she lost her sense of time and orientation, lasting up to an hour.

\section{Case 4: 'Ruth'}

Ruth is a 29-year-old woman with treatment-resistant BDD stemming from early emotional abuse by her father. She was also physically assaulted and raped at the age of 15 , and as a consequence suffers from severe and chronic PTSD. In addition, she experiences extreme mood swings and has been diagnosed with bipolar disorder and borderline personality disorder.

\section{Case 5: 'Esther'}

Esther is a 17-year-old adolescent with treatment-resistant OCD, which manifested as a need to feel just right and complete. She worried about 'leaving bits of herself or thoughts' behind. She constantly tapped and conducted mental rituals such as repeating words or sentences to 'store' them, with the result that she became stuck and often did not get to the toilet in time. She had a highly enmeshed relationship with her mother who over-protected her.

\section{Case 6: 'Hannah'}

Hannah is a 34-year-old British woman who suffered from chronic BDD and OCD since her early childhood, as a consequence of severe bullying by her stepfather. She experienced paranoid delusions, of both religious nature and persecutory paranoia (delusions of reference, fearing people would harm her because of her appearance). She had not left the house for 7 years prior to her admission. Her mother was her sole carer, who she had a disorganized attachment and troubled relationship with.

\section{Dimensions of complexity}

This section describes the following dimensions of complexity that frequently occur in clinical work with OCRDs, particularly in those with severe and longstanding problems, namely 
dissociation, family accommodation, psychosis, and personality and interpersonal difficulties. Each dimension is illustrated drawing on the cases presented above, and the respective interventions are described. Each case is complex in its own right with various overlapping dimensions.

Dissociation. Dissociative experiences are frequently experienced by those with more severe OCD (Grabe et al., 1999; Watson et al., 2004; Rufer et al., 2005; Semiz et al., 2014); but less is known about dissociation in BDD. Dissociation is generally described as a 'lack of integration of thoughts, feelings and experiences' (Bernstein and Putnam, 1986), and can take many different forms ranging from transient to chronic experiences of derealization, depersonalization (also described as 'detachment') to more amnesic experiences such as dissociative identity disorder (DID), or dissociative flashbacks (also described as 'compartmentalization', see Holmes et al., 2005). Dissociative phenomena occur more frequently in those with treatment-resistant OCD (Semiz et al., 2014), and predict poorer treatment outcome (Rufer et al., 2005). Dissociative disorders are common among OCD patients as recently found by Belli et al. (2012). They highlight that dissociative symptoms may hint at more chronic complex dissociative disorders such as depersonalization or DID, particularly in severe OCD, and conclude that poor treatment response may be a result of dissociative processes. Whether OCRD patients are prone to dissociation or whether those with elevated dissociation exhibit OCRD symptoms is, of course, difficult to establish.

How dissociative experiences add to complexity in OCRD is illustrated by Matt's, Ruth's and Hema's cases. Hema had years of unsuccessful CBT and E/RP that mostly focused on encouraging her to touch things she perceived as contaminated with small insects, such as bed sheets or cushions without decontamination. When small treatment gains enabled her to start dating and, for the first time in her life to become intimate with someone, her OCD and BDD rapidly deteriorated and full-blown PTSD emerged. She experienced daily dissociative flashbacks during which she became unresponsive and fully lost her sense of time and orientation, reliving early childhood sexual abuse inflicted on her by her father and brother, who kept her locked in her house until her mid-twenties during which time she was constantly raped and physically, as well as verbally, abused by them. Flashbacks were reliably triggered whenever she attempted to carry out an exposure task. For example, she perceived bed sheets contaminated with bugs and lice, and whenever she touched these collapsed in washing. She was also unable to lie down (because of body memories associated with being tied to her bed and raped), and whenever attempted to do so in sessions (as part of E/RP) experienced severe dissociative flashbacks. In treatment we hypothesized that her OCD, body shame and PTSD all stemmed from the extended sexual, physical and emotional abuse. We formulated that her OCD served the function of avoiding any trauma-related memories and associated body shame. Whenever her memories were triggered, particularly during exposure tasks she experienced dissociative flashbacks. Therefore, we reduced exposure tasks in favour of stabilizing her psychologically to enable trauma-focused work. Hema used lavender scents and music to ground herself when she noticed herself drifting into a flashback, and when already dissociated other residents played her favourite songs to her in order to help her come out of the reliving. She also practiced stimulus discrimination to facilitate contextualizing her trauma memories. We formulated all her safety seeking- and avoidance behaviours as understandable strategies with the function of keeping her safe, with the unintended consequences of preventing updating the trauma memory, and disconfirmation of threat-related beliefs. 
Similarly, Ruth, whose main diagnoses were BDD and bipolar disorder, also suffered from chronic PTSD and daily flashbacks stemming from a sexual assault at the age of 15 when she was raped and physically assaulted by a local workman. Her flashbacks were less noticeable than Hema's because she did not drift into prolonged reliving, and felt too ashamed to confide her trauma to professionals. However, in her case too, behavioural BDD work was greatly compromised by a chronic sense of trauma-related threat. For example, she felt constantly stalked by men (as the rapist had done), and therefore found going into the community for BDD exposures extremely difficult. Ruth heavily camouflaged with scarves and make-up with the aim of improving her appearance, but we discovered that it also served the function of changing her appearance to lower her perceived risk of attracting perpetrators. Following the rape she started to heavily skin-pick her face, initially motivated by a wish to clear her acne. However, her elaborate picking-routines enabled her to drift into a dissociated state that allowed her to tolerate trauma-related flashbacks, which she otherwise found too unbearable, thus functioning as a powerful avoidance of her memories. Because of shame and traumatic guilt it took Ruth 8 months in hospital to share her trauma with her therapist. Trauma-focused work, in particular, visiting the site of trauma, reliving and updating hotspots (moments of peak distress; see Ehlers et al., 2005), diminished flashbacks and persecutory delusions of reference, thus increasing her sense of safeness which in turn enabled her to engage more effectively in BDD work.

Matt also suffered from a variety of severe dissociative experiences but of a different nature, which significantly sabotaged his OCD treatment. We hypothesized that three main interconnected obstacles entirely prevented any treatment progress. First, Matt's chronic depersonalization and derealization rendered trauma work ineffective because he was unable to connect with any trauma-related emotions; second, whenever he resisted ritualizing after being triggered he gradually dissociated with slowed 'foggy' thinking until he collapsed in decontamination rituals; third, his DID as manifested by various distinct personalities, actively sabotaged treatment. Matt described himself as weak and 'abnormal' and often 'coped' by switching partially or fully into a 'powerful, intelligent, deceptive, controlling, manipulative and narcissistic' personality, which most of the time went unnoticed by staff and patients. Initially Matt appeared 'ready for change' and motivated to overcome his difficulties. Seemingly courageously he carried out plenty of exposure tasks at the beginning of treatment, often self-facilitated, and usually with peers from the hospital community. However, he never managed to resist subsequent decontamination rituals. When he had switched to 'powerful Matt' he was able to confront triggers bravely, but when attempting response prevention 'weak Matt' became more dominant again, thus setting him up for failure. His OCD was highly delusional in that he was truly convinced that exposures, particularly those relating to asbestos (deemed safe by therapists, such as walking past a nearby rugby club which had an asbestos roof), posed an intolerable health threat. His anxiety never habituated, and every additional exposure gradually increased his detachment and worsened his DP/DR, making him feel more disconnected from his feelings, others and the world around him. This new information required a change in his formulation, and we conceptualized his various forms of dissociation as understandable coping responses to overwhelming childhood distress. We hypothesized that as a result of severe attachment difficulties, isolation from peers and early trauma, he did not develop effective emotion regulation skills. In treatment we encouraged Matt to reduce E/RP and instead focused on building emotion regulation techniques that included developing mindfulness of bodily sensations associated with feelings, broadening 
his emotional vocabulary and compassionate-imagery to soothe and calm himself. Imagery rescripting aimed at processing relevant past traumatic experiences that were emotionally linked with his dissociative experiences. Even though Matt remembered miniature details of early abuse, he was unable to connect with any associated feelings, which greatly reduced the effectiveness of trauma processing.

Family accommodation. Family accommodation (FA) in OCRD is common. Family members or loved ones living or caring for a person with OCRDs are often pulled into rituals and avoidance behaviours. Research into FA is sparse but it has been found to predict poorer treatment outcome for OCD, and patients seem to improve more quickly if their family members receive a brief intervention to reduce accommodation (Stewart et al., 2008; Thompson-Hollands et al., 2015). FA may take several forms, ranging from seeking reassurance to demanding ritual participation or assistance in avoidance. Sometimes FA can take extreme forms to the point of a folie à deux, by which another person, usually someone who is having an intense relationship with the patient, partially or fully develops the symptoms of the patient (Grover and Gupta, 2006). Folie à deux are often described in the context of severe psychosis, but more recently have also been reported in the context of OCD (Mergui et al., 2010).

FA can render engagement and treatment significantly more complex, which is highlighted by Eric's and Esther's cases. In Esther's case, the family life entirely evolved around her OCD. Both parents were highly involved in prompting Esther all day to help her get unstuck from tapping and counting rituals, and providing reassurance that everything was fine and she did not need to worry about leaving bits of herself or thoughts behind. Esther's OCD served the function of avoiding difficult feelings, particularly sadness and anger stemming from bullying experiences; secondly we formulated that her OCD provided strong secondary gains by eliciting care from her mother who she appeared to have a strongly enmeshed relationship with. Effectively OCD prevented Esther from growing up and maturing into adulthood. We hypothesized that the enmeshment between mother and daughter was probably contributing to Esther's OCD, which in turn was also feeding their enmeshment. For example, Esther's OCD made her entirely co-dependent on her parents, and mother in particular. Esther relied on her to make simple daily decisions for her such as what to eat or what turn to take during a walk. We discovered that Esther only ever became stuck when she was around her parents or on the ward in close proximity to nursing staff, but never when she was out on her own. Her mother was highly protective of Esther and, understandably, worried about Esther getting stuck given the difficult shared and helpless experiences the family had with her OCD. Therefore, family interventions involved supporting the family to give Esther more responsibility and treat her more like an adult than a sick child. Once all prompts were removed, and when she started engaging in more value-based and age-appropriate activities (e.g. going out with friends, rather than with her mother), and making more decisions on her own (e.g. what to do in her free time, rather than relying on mum to make decisions for her), her OCD greatly improved.

Eric also had an enmeshed relationship with his mother, but of a different kind, in that their relationship had amounted to folie à deux. Prior to Eric's admission he was housebound for 7 years, spending most of his waking hours in the shower, assisted by his mother who would anxiously and dutifully comply with all OCD demands. His mother felt guilty for her son's suffering because she was emotionally unavailable when his OCD developed, due to her own mental health problems (PTSD following the war in Bosnia). When Eric's OCD 
worsened during his early adulthood, his mother became heavily involved in his rituals. Eric was constantly seeking reassurance from her whether he was contaminated ('Is this semen, or cotton?') or whether she had semen on her, usually demanding her to wash, change clothes, or clean the house. His mum bought cleaning products worth $£ 150$ a week, and constantly 'assisted' his shower rituals and 'helped' him with the washing. When Eric's OCD deteriorated he was forcefully demanding reassurance, and ordered his mother to overspend on products, and steal them when she could not afford them. Eric in turn felt guilty for his mother's growing debt, and for causing her distress. On the few occasions when his mother tried not to provide reassurance or resist giving into his demands such as re-cooking meals that Eric perceived as contaminated, he would stubbornly refuse to eat and starve himself for days. His mother's involvement went far beyond colluding with Eric's OCD. By the time Eric was admitted, she had entirely bought into Eric's belief system and had developed full-blown OCD herself, worrying about semen and showing marked disgust avoidance. She started wearing gloves and kept the house microscopically clean even though Eric was in hospital. Her OCD was entirely motivated by keeping herself clean to avoid contaminating her son and keeping him 'safe'. They had not hugged or touched each other for 7 years. During joint sessions they would keep a 'safety distance' of at least 1 metre, with Eric worrying that semen would magically transfer from him to his mother, and equally his mother would be worried and vigilant to not come close to him. Even when Eric agreed for joint exposures with his mother, she refused, explaining 'she was not ready yet'. During the first 3 months of Eric's admission she secretly smuggled OCD products into the hospital with the motivation of 'helping' her son cope in hospital, thus actively sabotaging his treatment. When Eric improved and stopped calling for reassurance, she became upset, feeling rejected and abandoned by Eric. Initially we started weekly joint sessions with mum with the view of formulating and normalizing their joint suffering, and to carry out joint exposures. This proved too difficult for mum who was too anxious to engage in exposures with her son, fearing that she would need to decontaminate herself with bleach afterwards. We therefore paused family work, and agreed for mum not to visit so that both could first improve in their individual treatments before resuming joint exposures. Nevertheless, mum continued to visit on weekends when the therapy team was not around with the motivation of 'helping' her son through providing reassurance and products. Only after we contracted with Eric and mum that their separation was an essential treatment intervention, her visits became less frequent, and allowed Eric to progress in his treatment. Figure 1 gives an overview of Eric's formulation, which demonstrates how we conceptualized his OCD, highlighting the intended function of each OCD behaviour and the unintended consequences of them; as well as how the different treatment components mapped onto the formulation.

Psychosis. Psychotic symptoms such as hearing voices, paranoia or mood swings are not uncommon in people suffering from severe OCD (Freeman et al., 2002; Perugi et al., 2002) or BDD (Gunstad and Phillips, 2003; Phillips, 2004). Rather than viewing psychotic and nonpsychotic variants of BDD as separate categories, a dimensional view of psychosis in BDD may be more accurate (Phillips, 2004). Co-morbid psychosis can make treatment of OCRDs significantly more complex, as illustrated by Ruth's and Hannah's cases.

Besides suffering from long-standing BDD, Ruth also had a diagnosis of bipolar disorder. She experienced rapidly cycling mood swings which made it difficult for her to engage in CBT for BDD, particularly when her mood was elated. Her BDD resulted from early severe 


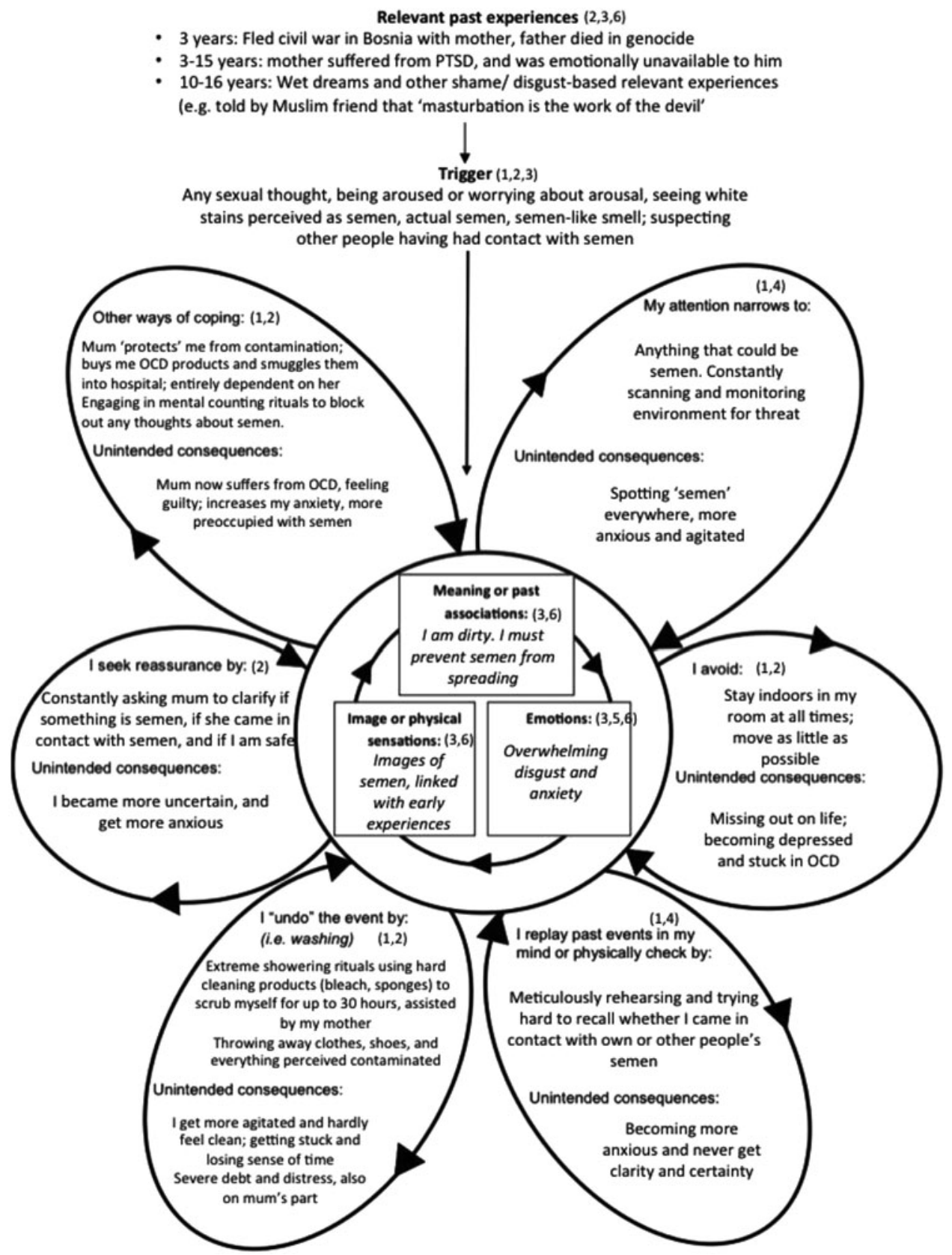

Fig. 1. Eric's formulation of the onset and maintenance of his OCD including the unintended consequences of each OCD behaviour. Numbers in parentheses denote the therapeutic intervention targeting the relevant OCD behaviour, process and/or experience: (1) exposure and response prevention; (2) joint sessions and exposures with mum; (3) imagery rescripting; (4) attentional training; (5) stimulus discrimination; (6) compassion-focused therapy. Eric's care approach was multidisciplinary; he had a care coordinator overseeing his care in the community. Eric also received occupational therapy, social skills training, employment support training, and moved to a residential care home to learn to live independently subsequent to his admission 
bullying about her appearance by her father, and her mother's failure to protect her from the abuse. From the age of 10 she experienced cycles of elated mood that could last for days, followed by periods of extremely low mood, and hopelessness. Even though she felt she had little control over the onset of a manic phase, she deliberately engaged in behaviours that kept her on a high, e.g. by choosing to listen to fast-beat music, by narrowing her visual attention on certain objects and purposefully telling herself amusing stories. Her mood swings deteriorated when she was assaulted and raped (aged 15), after which she went through years of being admitted to hospitals under the Mental Health Act for suicidality. Her 'giddiness' posed a significant obstacle to treatment because Ruth was reluctant to work on perpetuating high moods in therapy because 'it was too boring not to be high'. We formulated her elated mood as an unhelpful way of coping with appearance-related distress, low self-esteem and a constant sense of threat stemming from her trauma. In the literature this has been described as a 'manic defence' (Goldberg et al., 2008) although the concept is controversial (Scott et al., 2000). Treatment involved, besides the pharmacological approach, helping Ruth understand the unintended consequences of perpetuating highs (feeling disconnected from others, and others from her because she is perceived as inauthentic; preventing disconfirmation of negative beliefs; feeding mood swings, and inevitable depressive lows). She learned to build distress tolerance through emotion regulation. She also learned to ground herself using scents and soothing music, as well as compassion-focused mindful imagery.

In Hannah's case psychosis symptoms were complex in different ways. Besides her BDD and OCD she suffered from various paranoid ideas. On the one hand she had bought into a complex delusional system mainly featuring religious content and conspiratorial beliefs about the imminent 'end times'. She also suffered from delusions of reference of various complexities. She was convinced that others would harm her because of her unacceptable appearance, and she also feared that she was monitored by helicopters and that she was the target of supernatural forces that did not want to her to get better. She had reported a series of unusual experiences including sleep paralysis, which to her meant that she was the victim of a distant radio-energy attack. These delusions greatly interfered with her BDD and OCD treatment, as she was constantly preoccupied with them, and felt misunderstood by staff and patients which made her feel disconnected from the community.

Initially we attempted to work within her delusional system, i.e. instead of directly challenging it, we focused on helping her to come out of her room and engage with others. Hannah discovered that whenever she isolated herself and became withdrawn to her room her rumination increased, lowering her mood and increasing her paranoia. She felt ambivalent about giving up her delusional ideas. They had become a significant part of her identity, and even though her paranoia increased anxiety, the idea of giving up her delusional beliefs felt too isolating and depressing to her.

Personality and interpersonal difficulties. Personality disorders (PD) are common in OCD (Stekette, 1990; Torres et al., 2006; Lenzenweger et al., 2007) and BDD (Phillips and McElroy, 2000), and heightened personality traits, in particular of the OCPD spectrum, have also been found among family members (Samuels et al., 2000). A recent epidemiological study found that $73.8 \%$ of people with OCD $(n=108)$ met diagnostic criteria for at least one PD, with 53\% having more than one associated PD (Torres et al., 2006). Less research has looked at interpersonal difficulties in OCRDs. However, one recent epidemiological study found that BDD patients had significantly more interpersonal problems than those without 
BDD, particularly in the areas of social inhibition and non-assertiveness (Didie et al., 2012). It is often assumed in clinical practice that clients with personality difficulties benefit less from axis 1 treatment than those without PD. Therapists have also been found to hold unhelpful beliefs about clients with PD such as that they are difficult, less deserving of treatment or manipulative; and treatment challenges are often attributed to their supposed PDs (Lewis and Appleby, 1988). Despite these challenges, Weertman and colleagues (2005) found in their large prospective study of 398 anxiety out-patients with PD, that treatment of anxiety disorders in patients with concomitant one or more PDs is appropriate, and can be effective.

Personality and interpersonal difficulties can complicate treatment of OCRDs in many ways. For example, Matt suffered from OCPD and narcissistic traits (mostly related to his DID), adding substantial complexity to this presentation. His OCPD was characterized by an egosyntonic need for cleanliness, symmetry and order. He kept his house in an immaculate condition, in which he took great pride, although his preference for cleanliness was confounded with his contamination OCD. His need to 'have things my way' caused marital discord, in turn lowering his wife's motivation to support him and engage in treatment. His narcissistic tendencies and manipulative streaks associated with his alter personality caused unrest and ruptures in the community, which were time and energy consuming, and often diverted attention away from OCD treatment. This part of his personality was thriving on patients' setbacks, and took pleasure when others struggled in their recoveries. When switched he would flirt with vulnerable patients, and purposefully played on their anxieties. For example, Hannah had religious paranoid ideas, and Matt's alter personality would talk to her in an ancient Latin language to 'freak her out'. When Matt, in a courageous attempt to be more authentic and elicit compassionate support from the others, shared his DID formulation with the community, his peers distanced themselves from him, thereby further enraging his alter personality, and causing more isolation, low mood and hopelessness. Treatment aimed to help Matt understand changes in his emotional states and environmental demands that triggered personality switches, take ownership of the behaviour of all personalities, and use distress tolerance and emotion regulation. Imagery rescripting attempted to meet the unmet needs of his younger self that ultimately led to his dissociative and personality difficulties. However, his alter personality, which embodied his narcissistic traits, was not sufficiently engaged in treatment. Eventually the therapy team referred him for expert assessment and treatment of DID in a specialist clinic.

\section{Conclusion}

This paper explored various dimensions of 'complexity' in OCRDs. Rather than focusing on the content of obsessions and compulsions we emphasized the importance of formulating the client's difficulties as learned ways of coping that are highly understandable in the idiosyncratic context of the person's life. The function of safety-seeking and avoidance behaviours is usually threat-motivated and driven by the 'better safe than sorry' principle. While these strategies are entirely plausible given the client's personal experiences, they bring about a range of unintended consequences. For example, someone with BDD who covers their face in a scarf, or avoids eye contact, is more likely to misinterpret social cues, which in turn may feed their delusions of reference, as illustrated here by Hannah's case. Therefore, a good collaborative developmental formulation of the client's complex difficulties helps to normalize and engage them in treatment. When clients present with complex 
co-morbid difficulties such as dissociative phenomena, psychosis or personality difficulties, E/RP and CBT often fall short as they do not adequately address the emotional origins that may continue to affect the client's difficulties. We strongly recommend exploring past-present links, and help patients to process relevant early experiences if indicated as early as possible in treatment. Particularly when patients continue to dissociate or relive the past in forms of flashbacks or intrusive memories, trauma-focused work should be prioritized, including reliving and updating memory hotspots, stimulus discrimination (see Ehlers et al., 2004; Grey and Holmes, 2008), as well as imagery rescripting. For example, imagery rescripting has been successfully used recently in treating OCD patients who experienced intrusive obsessional images in OCD (Veale et al., 2015b) and BDD (Ritter and Stangier, 2016; Sündermann et al., 2016; Willson et al., 2016). Imagery rescripting was used in the treatment of all clients presented here, and has proven particularly effective when shame- or disgust-based memories were driving rituals, and these were often linked with early childhood trauma. Note that imagery rescripting is not usually used to address intrusive memories but to change the meaning of relevant past childhood experiences that continue to shape a client's experience (Arntz, 2011). Most patients with complex OCRD are likely to continue suffering from unmet childhood needs, whether these are protection from abuse, emotionally unresponsive parents, or the over-valuation of appearance, which in turn not only drives OCRD behaviours but also shapes one's social and interpersonal experiences, and manifests as personality and relational difficulties.

Traumatic experiences are common among OCRD sufferers (Lochner et al., 2002; Didie et al., 2006; Gershuny et al., 2008; Mathews et al., 2008; Buhlmann et al., 2012), and from our experience, this is particularly true for people with complex presentations as demonstrated in this article, with some of them resembling complex trauma or PTSD presentations (see Hema's, Matt's and Ruth's cases). There is a debate in the literature about how best to conceptualize complex PTSD (Cloitre et al., 2011), which is characterized by core symptoms of PTSD plus pervasive impairments in affective, self- and relational functioning, emotion regulation and difficulties maintaining relationships. In line with treatment recommendations for complex PTSD by the International Society for Traumatic Stress (see Cloitre et al., 2011), we used a phased-approach, namely helping patients to stabilize before engaging in traumafocused work. However, it has recently been argued that the evidence base for such a phased approach is not conclusive (De Jongh et al., 2016).

A contextual functional approach rooted in evolutionary psychology has recently been put forward by Veale and Gilbert (2014), conceptualizing BDD behaviours as understandable coping ways in response to a perceived threat of a distorted body image and past aversive experiences. This had been helpful in engaging Ruth and Hannah, who both developed threatbased safety strategies that functioned to monitor and avoid social threats of shame and rejection, which they both developed in response to humiliation and bullying. Clients can find it helpful to emphasize that our brains are complicated and that the client's suffering is not their fault, albeit it is their responsibility to do something about it. Self-soothing and self-compassion skills can be helpful supplements to CBT in order to deshame relevant past experiences and help clients to disengage from threat monitoring and self-attacking thinking.

Furthermore, patients with complex OCRD often cannot function on their own and rely on family members or carers who often become part of the obsessional system, sometimes to the point of a folie à deux, as illustrated by Eric's case. Including the family members in therapy is pivotal for treatment success; however, family sessions focusing on 
Table 1. Treatment recommendations for complex OCRD

Treatment of complex OCRD

- A thorough developmental formulation is key, linking current suffering to past experiences

- Cross-sectional formulations should describe the context and the function of each coping behaviour, and its unintended consequences

- Trauma-focused work should be prioritized over behavioural interventions as soon as patients are stable enough, including reliving and updating of hotspots, imagery rescripting and stimulus discrimination

- Compassion-focused interventions may be a helpful adjunct to CBT

- Where possible, relevant others should always be included in therapy

psycho-education, shared understanding and joint exposures may not be enough; and as in Eric's case, his mother required her own individual CBT to help her overcome her OCD. Finally, treatment of complex OCRD may require more care resources than usually available in standard out-patient settings. This may include more frequent, flexible and intensive therapy sessions delivered by a therapist with specialist skills in treating complexity, often within a multidisciplinary care team, and/or a residential or in-patient setting, particularly in the context of past treatment failures, high risk or if the number and duration of sessions is limited due to funding constraints. Therapists seeing clients with complex difficulties as described in this paper may need to consider referrals to specialist clinics. Lastly, there is a lack of research examining efficacy of treatment for complex OCRD.

Recent outcome data from specialist OCRD clinics report exclusively on treatment outcome for OCRD on severity and treatment-resistance, but not complexity. While it is highly likely that these clinical samples entail patients with complex problems, complexity remains underresearched. We estimate that complexity is common in OCRD specialist clinics with around $50 \%$ of clients suffering from complex OCRD, as described here, particularly in in-patient and residential settings. In the entire OCRD population, complexity is likely to be much rarer, and we estimate the frequency to be around 5-10\%. We propose that future research should aim to clarify definitions of complexity, establish prevalence rates, and investigate more rigorously mechanisms of change in the treatment of complex OCRD, using single-case experimental designs, case studies and controlled trials. Future studies should also clarify terminology more stringently and differentiate more clearly between 'complexity', 'severity' and 'chronicity' as proposed in this article.

Table1 highlights some current conclusions and recommendations on how to work with complex OCRD.

\section{Main points}

(1) This paper describes how complexity in OCRD arises, the challenges various dimensions of complexity pose to therapy, how they are inter-linked, and how best to work with them, namely through understanding and processing relevant past experiences, the context and the function of coping behaviours, and drawing on compassion focused techniques, as well as family work whenever possible.

(2) Trauma-focused work should be prioritized when dissociation and re-experiencing are evident. 


\section{Ethical statements}

The authors of this paper have abided by the Ethical Principles of Psychologists and Code of Conduct as set out by the APA. No ethical clearance was required because clinical observations reported here are retrospective descriptions of clinical findings. Clients consented to the publication of their case material, and their care approach did not differ from the other clients seen in our service.

\section{Conflicts of interest}

Oliver Sündermann and David Veale have no conflicts of interest with respect to this publication.

\section{Financial support}

D.V. acknowledges salary support from the National Institute for Health Research (NIHR) Biomedical Research Centre for Mental Health at South London and Maudsley NHS Foundation Trust (SLAM) and the Institute of Psychiatry (IoP), King's College London. NIHR, SLAM and IoP had no role in the study design, writing of the manuscript or the decision to submit this paper for publication. This research received no specific grant from any funding agency, commercial or not-for-profit sectors.

\section{Recommended follow-up reading}

Sookman D (2015). Specialized Cognitive Behavior Therapy for Obsessive Compulsive Disorder: An Expert Clinician Guidebook. Routledge.

Veale D, Gilbert P (2014). Body dysmorphic disorder: the functional and evolutionary context in phenomenology and a compassionate mind. Journal of Obsessive-Compulsive and Related Disorders 3, 150-160.

Veale D, Gilbert P, Wheatley J, Naismith I (2014). A new therapeutic community: development of a compassion-focused and contextual behavioural environment. Clinical Psychology and Psychotherapy 22, 285-303.

\section{References}

Abramowitz JS, Franklin ME, Schwartz SA, Furr JM (2003). Symptom presentation and outcome of cognitive-behavioral therapy for obsessive-compulsive disorder. Journal of Consulting and Clinical Psychology 71, 1049.

Arntz A (2011). Imagery rescripting for personality disorders. Cognitive and Behavioral Practice 18, 466-481.

Arnone D, Patel A, Tan GMY (2006). The nosological significance of Folie à Deux: a review of the literature. Annals of General Psychiatry 5, 11.

Belli H, Ural C, Vardar MK, Yesilyurt S, Oncu F (2012). Dissociative symptoms and dissociative disorder comorbidity in patients with obsessive-compulsive disorder. Comprehensive Psychiatry 53, 975-980.

Bernstein EM, Putnam FW (1986). Development, reliability, and validity of a dissociation scale. Journal of Nervous and Mental Disease 174, 727-735. 
Boschen MJ, Drummond LM (2012). Community treatment of severe, refractory obsessivecompulsive disorder. Behaviour Research and Therapy 50, 203-209.

Buhlmann U, Marques LM, Wilhelm S (2012). Traumatic experiences in individuals with body dysmorphic disorder. Journal of Nervous and Mental Disease 200, 95-98.

Cloitre M, Courtois CA, Charuvastra A, Carapezza R, Stolbach BC, Green BL (2011). Treatment of complex PTSD: results of the ISTSS expert clinician survey on best practices. Journal of Traumatic Stress 24, 615-627.

De Jongh A, Resick PA, Zoellner LA, van Minnen A, Lee CW, Monson CM, Bicanic IAE (2016). Critical analysis of the current treatment guidelines for complex PTSD in adults. Depression and Anxiety 33, 359-369.

Didie ER, Loerke EH, Howes SE, Phillips KA (2012). Severity of interpersonal problems in individuals with body dysmorphic disorder. Journal of Personality Disorders 26, 345.

Didie ER, Tortolani CC, Pope CG, Menard W, Fay C, Phillips KA (2006). Childhood abuse and neglect in body dysmorphic disorder. Child Abuse and Neglect 30, 1105-1115.

Drummond LM, Fineberg NA, Heyman I, Kolb PJ, Pillay A, Rani S et al. (2008). National service for adolescents and adults with severe obsessive-compulsive and body dysmorphic disorders. The Psychiatrist 32, 333-336. http://doi.org/10.1192/pb.bp.107.017517

Ehlers A, Clark DM, Hackmann A, McManus F, Fennell M (2005). Cognitive therapy for posttraumatic stress disorder: development and evaluation. Behaviour Research and Therapy 43, 413431.

Ehlers A, Hackmann A, Michael T. (2004). Intrusive re-experiencing in post-traumatic stress disorder: phenomenology, theory, and therapy. Memory 12, 403-415.

Foa EB, Abramowitz JS, Franklin ME, Kozak MJ (1999). Feared consequences, fixity of belief, and treatment outcome in patients with obsessive-compulsive disorder. Behavior Therapy 30, $717-$ 724.

Freeman MP, Freeman SA, McElroy SL (2002). The comorbidity of bipolar and anxiety disorders: prevalence, psychobiology, and treatment issues. Journal of Affective Disorders 68, 1-23.

Frost RO, Steketee G (2002). Cognitive Approaches to Obsessions and Compulsions: Theory, Assessment and Treatment. Elsevier.

Gershuny BS, Baer L, Parker H, Gentes EL, Infield AL, Jenike MA (2008). Trauma and posttraumatic stress disorder in treatment-resistant obsessive-compulsive disorder. Depression and Anxiety 25, 69-71.

Gilbert P (1998). The evolved basis and adaptive functions of cognitive distortions. British Journal of Medical Psychology 71, 447-463.

Goldberg JF, Gerstein RK, Wenze SJ, Welker TM, Beck AT (2008). Dysfunctional attitudes and cognitive schemas in bipolar manic and unipolar depressed outpatients: Implications for cognitively based psychotherapeutics. Journal of Nervous and Mental Disease 196, 207-210.

Grabe HJ, Goldschmidt F, Lehmkuhl L, Gänsicke M, Spitzer C, Freyberger HJ (1999). Dissociative symptoms in obsessive-compulsive dimensions. Psychopathology 32, 319324.

Grey N, Holmes EA (2008). 'Hotspots' in trauma memories in the treatment of post-traumatic stress disorder: a replication. Memory 16, 788-796.

Grover S, Gupta N (2006). Shared obsessive-compulsive disorder. Psychopathology 39, 99-101.

Gunstad J, Phillips KA (2003). Axis I comorbidity in body dysmorphic disorder. Comprehensive Psychiatry 44, 270-276.

Holmes EA, Brown RJ, Mansell W, Fearon RP, Hunter EC, Frasquilho F, Oakley DA (2005). Are there two qualitatively distinct forms of dissociation? A review and some clinical implications. Clinical Psychology Review 25, 1-23.

Lenzenweger MF, Lane MC, Loranger AW, Kessler RC (2007). DSM-IV personality disorders in the National Comorbidity Survey Replication. Biological Psychiatry 62, 553-564. 
Lewis G, Appleby L (1988). Personality disorder: the patients psychiatrists dislike. British Journal of Psychiatry 153, 44-49.

Lochner C, du Toit PL, Zungu-Dirwayi N, Marais A, van Kradenburg J, Seedat S, Niehaus DJ, Stein DJ (2002). Childhood trauma in obsessive-compulsive disorder, trichotillomania, and controls. Depression and Anxiety 15, 66-68.

Marks IM (1987). Fears, Phobias and Rituals: Panic, Anxiety and their Disorders. Oxford University Press on Demand.

Mason EC, Richardson R (2010). Looking beyond fear: the extinction of other emotions implicated in anxiety disorders. Journal of Anxiety Disorders 24, 63-70.

Mathews CA, Kaur N, Stein MB (2008). Childhood trauma and obsessive-compulsive symptoms. Depression and Anxiety 25, 742-751.

McKay D, Abramowitz JS, Calamari JE, Kyrios M, Radomsky A, Sookman D, Taylor S, Wilhelm S (2004). A critical evaluation of obsessive-compulsive disorder subtypes: symptoms versus mechanisms. Clinical Psychology Review 24, 283-313.

Melli G, Chiorri C, Carraresi C, Stopani E, Bulli F (2015). The two dimensions of contamination fear in obsessive-compulsive disorder: harm avoidance and disgust avoidance. Journal of Obsessive-Compulsive and Related Disorders 6, 124-131.

Mergui J, Jaworowski S, Greenberg D, Lerner V (2010). Shared obsessive-compulsive disorder: broadening the concept of shared psychotic disorder. Australian and New Zealand Journal of Psychiatry 44, 859-862.

Olatunji BO, Wolitzky-Taylor KB, Willems J, Lohr JM, Armstrong T (2009). Differential habituation of fear and disgust during repeated exposure to threat-relevant stimuli in contamination-based OCD: an analogue study. Journal of Anxiety Disorders 23, 118-123.

Osman S, Cooper M, Hackmann A, Veale D (2004). Spontaneously occurring images and early memories in people with body dysmorphic disorder. Memory 12, 428-436.

Perugi G, Toni C, Frare F, Travierso MC, Akiskal HS (2002). Obsessive-compulsive-bipolar comorbidity: a systematic exploration of clinical features and treatment outcome [CME]. Journal of Clinical Psychiatry 63, 1129-1134.

Phillips KA (2004). Psychosis in body dysmorphic disorder. Journal of Psychiatric Research 38, 63-72.

Phillips KA, McElroy SL (2000). Personality disorders and traits in patients with body dysmorphic disorder. Comprehensive Psychiatry 41, 229-236.

Rachman S (2010). Betrayal: a psychological analysis. Behaviour Research and Therapy 48, 304311.

Ritter V, Stangier U (2016). Seeing in the mind's eye: imagery rescripting for patients with body dysmorphic disorder. A single case series. Journal of Behavior Therapy and Experimental Psychiatry 50, 187-195.

Rosen JC, Reiter J, Orosan P (1995). Cognitive-behavioral body image therapy for body dysmorphic disorder. Journal of Consulting and Clinical Psychology 63, 263-269.

Rufer M, Fricke S, Moritz S, Kloss M, Hand I (2006). Symptom dimensions in obsessivecompulsive disorder: prediction of cognitive-behavior therapy outcome. Acta Psychiatrica Scandinavica 113, 440-446.

Rufer M, Held D, Cremer J, Fricke S, Moritz S, Peter H, Hand I. (2005). Dissociation as a predictor of cognitive behavior therapy outcome in patients with obsessive-compulsive disorder. Psychotherapy and Psychosomatics 75, 40-46.

Samuels J, Nestadt G, Bienvenu OJ, Costa PT, Riddle MA, Liang KY, Hoehn-Saric R, Grados MA, Cullen BA. (2000). Personality disorders and normal personality dimensions in obsessivecompulsive disorder. British Journal of Psychiatry 177, 457-462.

Scott J, Stanton B, Garland A, Ferrier IN (2000). Cognitive vulnerability in patients with bipolar disorder. Psychological Medicine 30, 467-472. 
Semiz UB, Inanc L, Bezgin CH (2014). Are trauma and dissociation related to treatment resistance in patients with obsessive-compulsive disorder? Social Psychiatry and Psychiatric Epidemiology 49, 1287-1296.

Speckens AE, Hackmann A, Ehlers A, Cuthbert B (2007). Imagery special issue: intrusive images and memories of earlier adverse events in patients with obsessive compulsive disorder. Journal of Behavior Therapy and Experimental Psychiatry 38, 411-422.

Stekette G (1990). Personality traits and disorders in obsessive-compulsives. Journal of Anxiety Disorders 4, 351-364.

Stewart SE, Beresin C, Haddad S, Egan Stack D, Fama J, Jenike M (2008). Predictors of family accommodation in obsessive-compulsive disorder. Annals of Clinical Psychiatry 20, $65-70$.

Sündermann O, Wheatley J, Veale D (2016). 'If you have good skin, you are god. If you have bad skin, you are a piece of rubbish' - Mastery of shame and anger in treatment-resistant body dysmorphic disorder: a single case study. the Cognitive Behaviour Therapist 9, 1-18.

Thompson-Hollands J, Abramovitch A, Tompson MC, Barlow DH (2015). A randomized clinical trial of a brief family intervention to reduce accommodation in obsessive-compulsive disorder: a preliminary study. Behavior Therapy 46, 218-229.

Tolin DF, Maltby N, Diefenbach GJ, Hannan SE, Worhunsky P (2004). Cognitive-behavioral therapy for medication nonresponders with obsessive-compulsive disorder: a wait-list-controlled open trial. Journal of Clinical Psychiatry 65, 922-931.

Torres AR, Moran P, Bebbington P, Brugha T, Bhugra D, Coid JW, Farrel M, Jenkis R, Lewis G, Meltzer H, Prince M (2006). Obsessive-compulsive disorder and personality disorder. Social Psychiatry and Psychiatric Epidemiology 41, 862-867.

Veale D, Anson M, Miles S, Pieta M, Costa A, Ellison N (2014). Efficacy of cognitive behaviour therapy versus anxiety management for body dysmorphic disorder: a randomised controlled trial. Psychotherapy and Psychosomatics 83, 341-353.

Veale D, Gilbert P (2014). Body dysmorphic disorder: The functional and evolutionary context in phenomenology and a compassionate mind. Journal of Obsessive-Compulsive and Related Disorders 3, 150-160.

Veale D, Gournay K, Dryden W, Boocock A, Shah F, Willson R, Walburn J (1996). Body dysmorphic disorder: a cognitive behavioural model and pilot randomised controlled trial. Behaviour Research and Therapy 34, 717-729.

Veale D, Naismith I, Miles S, Childs G, Ball J, Muccio F, Darnley S (2015a). Outcome of intensive cognitive behaviour therapy in a residential setting for people with severe obsessive compulsive disorder: a large open case series. Behavioural and Cognitive Psychotherapy 44, 331346.

Veale D, Naismith I, Miles S, Gledhill LJ, Stewart G, Hodsoll J (2016). Outcomes for residential or inpatient intensive treatment of obsessive-compulsive disorder: a systematic review and metaanalysis. Journal of Obsessive-Compulsive and Related Disorders 8, 38-49.

Veale D, Page N, Woodward E, Salkovskis P (2015b). Imagery rescripting for obsessive compulsive disorder: a single case experimental design in 12 cases. Journal of Behavior Therapy and Experimental Psychiatry 49, 230-236.

Warnock-Parkes E, Salkovskis PM, Rachman J (2012). When the problem is beneath the surface in ocd: the cognitive treatment of a case of pure mental contamination. Behavioural and Cognitive Psychotherapy 40, 383-399.

Watson D, Wu KD, Cutshall C (2004). Symptom subtypes of obsessive-compulsive disorder and their relation to dissociation. Journal of Anxiety Disorders 18, 435-458.

Weertman A, Arntz A, Schouten E, Dreessen L (2005). Influences of beliefs and personality disorders on treatment outcome in anxiety patients. Journal of Consulting and Clinical Psychology 73, 936-944. 
Wilhelm S, Phillips KA, Didie E, Buhlmann U, Greenberg JL, Fama JM, Keshaviah A, Steketee G (2014). Modular cognitive-behavioral therapy for body dysmorphic disorder: a randomized controlled trial. Behavior Therapy 45, 314-327.

Willson R, Veale D, Freeston M (2016). Imagery rescripting for body dysmorphic disorder: a multiple-baseline single-case experimental design. Behavior Therapy 47, 248-261.

\section{Learning objectives}

(1) OCRD complexity may arise in the context of dissociation, family accommodation, personality problems and psychosis.

(2) Understanding and processing past relevant experiences may be key for treatment success.

(3) Considering the function, context and unintended consequences of coping behaviours may increase engagement and treatment effectiveness.

(4) Trauma-focused work should be prioritized when re-experiencing is evident.

(5) Imagery rescripting and compassion focused techniques may enhance CBT. 